\title{
Computer-Aided Exergy Study of a Gas Microturbine Cogeneration System
}

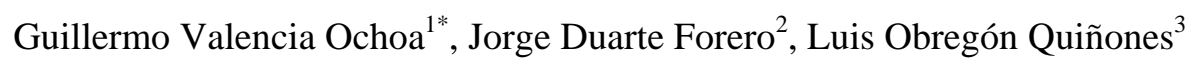 \\ ${ }^{1}$ Efficient Energy Management Research Group, Universidad del Atlántico, \\ km 7Antigua vía Puerto, Colombia \\ ${ }^{2}$ DIMER Research Group, Universidad del Atlántico, \\ km 7 Antigua vía Puerto, Colombia \\ ${ }^{3}$ Research Group on Sustainable Chemical and Biochemical Processes, Universidad del Atlántico, \\ km 7 Antigua vía Puerto, Colombia \\ *guillermoevalencia@mail.uniatlantico.edu.co
}

\begin{abstract}
In the following article, an exergetic analysis of a microturbine operating with a regenerative Brayton cycle was carried out in order to identify the variation in exergy and exergy destruction behaviour generated in each component of the system by comparing these results to different microturbine loads. The study was carried out on a Brayton cycle with cogeneration which is composed of a compressor, combustion chamber, gas turbine, HRSG and an air preheater. In which the output power of the turbine was varied for the five case studies starting at $25 \mathrm{~kW}$ to $45 \mathrm{~kW}$. As the study is carried out, at $45 \mathrm{~kW}$ the greatest exergy is consumed and in the combustion chamber it is the one that contributes most to the destruction of exergy, adding up to an average of $36.5 \%$ of the total destroyed. With this it was shown that the increase of the power output of the turbine increases the needs of each component of the system and also increases the exertions of the system.
\end{abstract}

Keywords - Computer-aided simulation, cogeneration system, microturbine, exergetic performance.

\section{INTRODUCTION}

One of the thermodynamic cycles used for power generation is the Brayton Cycle, which uses gas, diesel or light fuels as fuel. These cycles have been studied in order to improve their performance[1-4]. In these cycles the simulation performance has been improved, modifying some parameters such as mass flow in the equipment, in order to achieve maximum power and less exergy destruction[5].

In the case of a regenerative Brayton cycle, where the difference with the original is that the flow of hot air does not fully expand to atmospheric pressure before entering the regenerator, the improvement obtained has allowed to achieve a thermal efficiency between $12 \%$ and $26 \%[6]$. In addition, it has been demonstrated that the dimensionless power of the cycle can be optimized by looking for both the optimum heat transfer distributions between the hot and cold side of the heat exchanger and the optimum pressure ratio between the equipment[7]. However, all the proposed improvements found for these systems lead to smaller engine components such as compressors, turbine, regenerator and heat exchanger[8].

In addition, other studies have made it possible to optimize the entropy generation rate by $70 \%$ through the use of an ecological optimization function, bringing power generation close to the maximum capacity of the equipment defined by its design conditions[9].

One criterion for optimising Brayton cycles is the thermosetting analysis[10-12], where the total cost analysis takes into account the cost of fuel, investment, environment, operation and maintenance, as well as irreversibilities due to finite rate heat transfer, internal dissipations and pressure drops[13]. This criterion under the thermo-economical approach was used in a gas power generation system, allowing to identify an optimal point of operation where an efficiency of $71 \%$ of the maximum power was reached by means of multiple objective optimization functions, an exergy destruction of $24 \%$ lower and $67 \%$ less in the total cost with respect to the standard operating conditions[14].

Exergetic analysis as a means of searching for improvement opportunities is an important method of cycle optimization that has been widely used for different processes[15-17].In the same way, for a new configuration of the proposed regenerative Brayton cycle, an exergy analysis was performed, the performance of the new configuration was investigated and optimized, and the optimum cooling pressure was determined [18]. In addition, the use of exergetic analysis allows us to evaluate the feasibility of integrating a closed combined cycle based on Brayton cycles with a solar power plant, resulting in exergetic efficiencies of over 70\% [19].

Therefore, the main contribution of this work is to present the results of applying an exergetic analysis of a microturbine operating with a regenerative Brayton cycle, in order to identify the variation of exergy destruction behaviors and exergy generated in each component of the system, by comparing these results to different loads of the microturbine. 


\section{METHODOLOGY}

The following is a detailed description of the process, which emphasizes the main components of the process and the case studies developed, as well as a diagram of the equipment and the fundamental equations that allowed for the caculation of the physical and chemical exertions and the destruction of exergy in the components.

\subsection{Process description}

The following is a detailed description of the process, which emphasizes the main components of the process and the case studies developed, as well as a diagram of the equipment and the fundamental equations that allowed for the caculation of the physical and chemical exertions and the destruction of exergy in the components Figure 1.

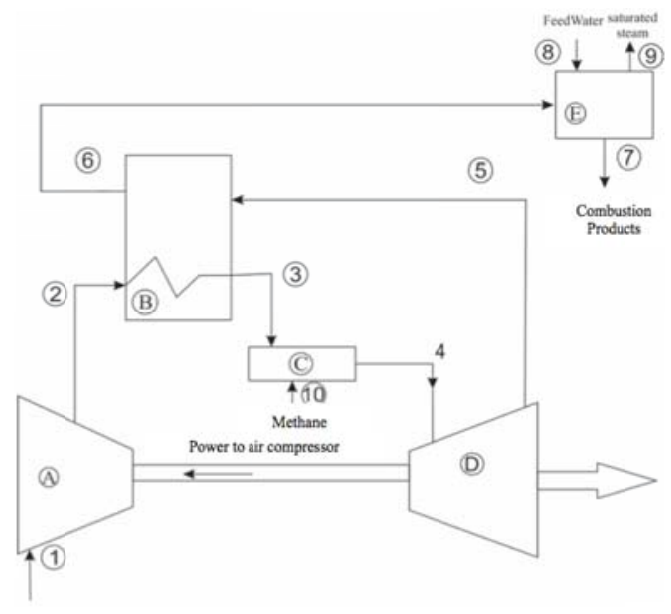

Figure 1. Process Diagram

For this system the output power of the turbine is varied for the five case studies shown in theTable 1 , with the aim of evaluating the behavior of the chemical and physical exertions and the exergy destroyed in each of these cases.

Table 1. Variation of operational parameters

\begin{tabular}{cc}
\hline Case & Power output (kW) \\
\hline 1 & 25 \\
2 & 30 \\
3 & 35 \\
4 & 40 \\
5 & 45 \\
\hline
\end{tabular}

\subsection{Fundamental Equations}

The fundamental thermodynamic equations used in this study have been extensively studied and are available in the literature[20],which together with the energy and exergy balances allow us to study the behavior of the cycle.The first law of thermodynamics for an open, steady state system was applied to each of the devices obtaining equation (1).

$$
\dot{Q}_{C . V .}+\sum \dot{m}_{l}\left(h_{i}+\frac{V_{i}^{2}}{2}+g \cdot Z_{i}\right)=\sum \dot{m}_{e}\left(h_{e}+\frac{V_{e}^{2}}{2}+g \cdot Z_{e}\right)+\dot{W}_{C . V .} \text { (1) }
$$

In addition, the second law states that for systems for constant flow in steady state the balance is that shown by equation (2).

$$
\sum_{j} \frac{\dot{Q}_{j}}{T_{j}}+\sum_{i} \dot{m}_{i} \cdot s_{i}-\sum_{e} \dot{m}_{e} \cdot s_{e}+\dot{S}_{g e n}=0
$$

Isotropic efficiency for turbines is given by the ratio between the actual power and the power generated by isentropic expansion and between the actual power at the input and that required by isentropic compression for compressors as shown in equations (3) and (4).

$$
\eta_{s t}=\frac{\dot{W}_{C V}}{\left(\dot{W}_{C V}\right)_{s}^{\prime}}
$$




$$
\eta_{s c}=\frac{\left(\dot{W}_{C V}\right)_{s}}{\dot{W}_{C V}} .(4)
$$

For ideal gases, the analysis of entropy between two states is governed by equation (5).

$$
\bar{s}\left(T_{2}, P_{2}\right)-\bar{s}\left(T_{1}, P_{1}\right)=\bar{s}^{\circ}\left(T_{2}\right)-\bar{s}^{\circ}\left(T_{1}\right)-\bar{R} \cdot \ln \frac{P_{2}}{P_{1}} .(5)
$$

According to the third law of thermodynamics entropy at the same temperature and any pressure for ideal gases is determined according to equation (6).

$$
\bar{s}(T, P)=\bar{s}^{\circ}(T)-\bar{R} \cdot \ln \frac{P}{P_{\text {ref }}} .
$$

Exergy can be divided into physical exergy $\left(e^{P H}\right)$, potential exergy $\left(e^{P T}\right)$, kinetic exergy $\left(e^{K N}\right)$ and chemical exergy $\left(e^{\mathrm{CH}}\right)$ and omitting nuclear, magnetic, electrical and surface tension effects its equation (7) The total exergy specified in units of mass is.

$$
e=e^{P H}+e^{K N}+e^{P T}+e^{C H} .
$$

The physical exergy of a closed system in a specific state is given by equation (8), where $\mathrm{h}$ and $\mathrm{s}$ denote, respectively, the enthalpy and entropy of the system in the specific state, $h_{0}$ and $s_{0}$ are the values of the same properties when the system is in a restricted dead state.

$$
E^{P H}=\left(h-h_{0}\right)-T_{0}\left(S-S_{0}\right) .(8)
$$

The chemical exergy of a mixture of gases, which are present in the gaseous phase of the environment, can be obtained by means of equation (9).

$$
e^{-C H}=\overline{-R} T_{0} \sum x_{k} \ln \frac{x_{k}^{e}}{x_{k}} \cdot(9)
$$

\section{RESULTS AND ANALYSIS}

One of the parameters analyzed was the physical exergy which was studied in each of the states of the plant. Figure 1 shows a comparison of physical exergy in each state.

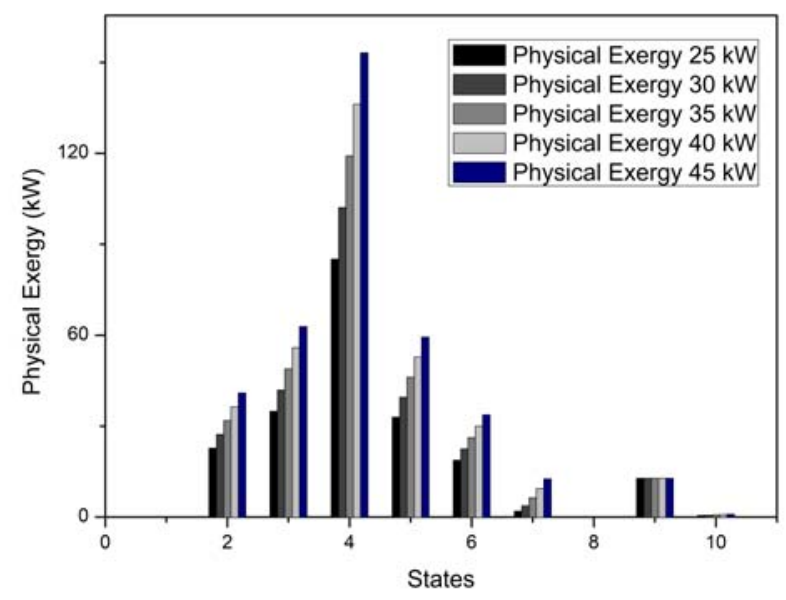

Figure 2. Physical exergy for states

In addition, the physical exergy is shown for each power ranging from $25 \mathrm{~kW}$ to $45 \mathrm{~kW}$. It was possible to observe that in the first state there is no exergy due to the fact that it is air at room temperature and therefore does not present an energetic potential. On the other hand, in state four a peak of exergy is observed since in this state the gases have just left the combustion chamber having here if higher temperature, this thermal condition is reflected in a great available energy which is used in the process of the plant. The increase of this temperature is a determining point for the design of these cycles, this is due to the fact that as the temperatures handled by the plant increase, the demands on the materials with which they are built increase and the costs of assembling the plant also increase.On the other hand, chemical exergy was also a parameter that was reviewed in the study. In states 4 to 7 the chemical exergy maintains the value reached after leaving the combustion chamber as shown in Figure 3. 


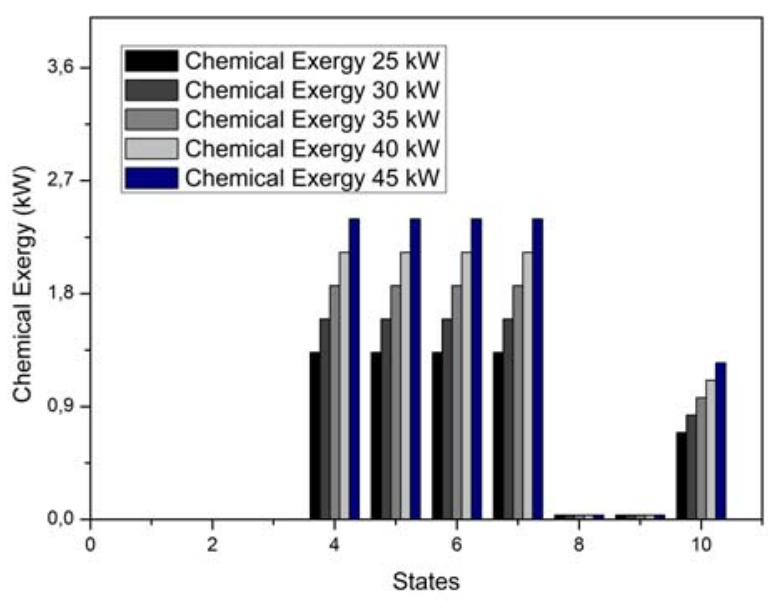

Figure 3. Chemical exergy for states

This result is due to the absence of a subsequent chemical reaction which can cause a decrease in chemical exergy. In addition, this figure shows the highest peak of chemical exergy in state 10 being this state where methane is injected into the combustion chamber. These values are multiplied by a factor of $10^{-2}$ for better visualization in the figure.

In the same way, the values of total exergy in each of the states were reviewed, this value is given by the sum of chemical and physical exergy. Figure 4 shows two high peaks due to the influence of high chemical exergy in state 10 due to the energy potential of methanol and physics in state 4 due to the increase in temperature generated by the passage of methanol through the combustion chamber.

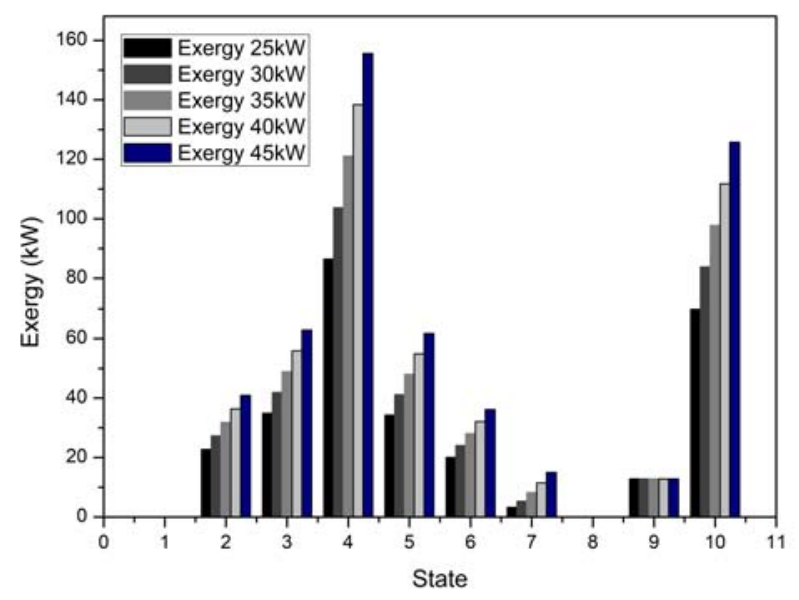

Figure 4. Total Exergy for states

Similarly, the exergy destruction obtained in each component was analyzed and a comparison is made with the total destruction of the components as shown in Figure 5. 


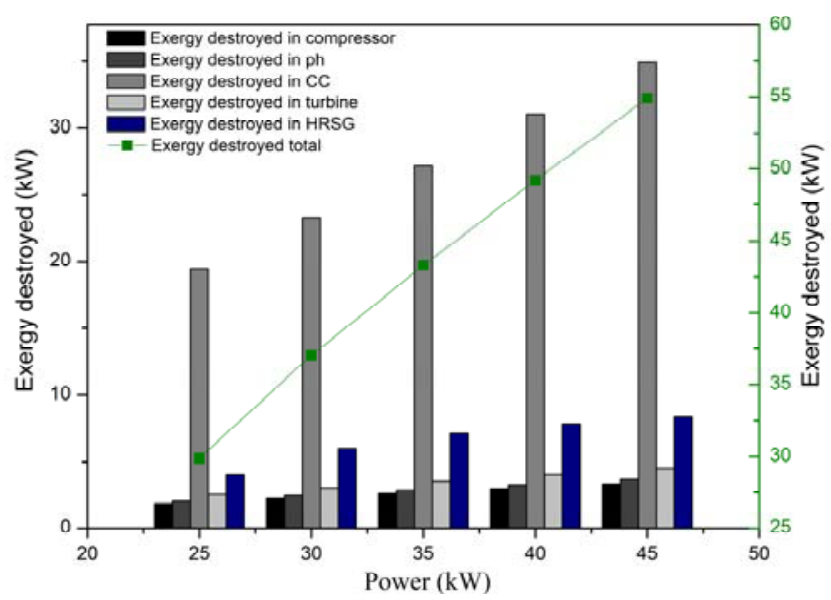

Figure 5. Exergy destroyed for output

The component that most contributes to the destruction of exergy is the combustion chamber. This destruction is presented in this component due to the transformation of the energy potential into methanol which is used to generate an increase in the temperature in the chamber. Adding up an average of $36.5 \%$ of the total destroyed exergy, its contribution to the destruction is very significant. This component shows its highest peak at $45 \mathrm{~kW}$.

Finally, Table 2 showed how fuel flow needs changed in each of the case studies. An increase proportional to the change in output power was observed, and as always the air flow was on average $1.72 \%$ lower than that of the products.

Table 2. Mass flow per power output

\begin{tabular}{ccc}
\hline Power (kW) & Product flow & Air flow \\
\hline 25 & 77,3454 & 76,0115 \\
30 & 92,8145 & 91,2139 \\
35 & 108,2836 & 106,4162 \\
40 & 123,7527 & 121,6185 \\
45 & 139,2218 & 136,8208 \\
\hline
\end{tabular}

\section{CONCLUSIONS}

In conclusion, this study showed how the increase in turbine output power increases the needs of each component of the system. Parameters such as fuel mass flows increase and the temperature handled by the system components increases, which is critical for the design considerations of the system. In addition, it is observed that as the power generated increases, both the chemical exergy in the fuel and the physical exergy after combustion increase proportionally, due to the increase in the mass flows previously mentioned. It is hoped that the results of this study will serve as a basis for further research focused on the Brayton cycle with microturbines.

\section{REFERENCES}

[1] Galindo J, Guardiola C, Dolz V, Kleut P. Further analysis of a compression-expansion machine for a Brayton Waste Heat Recovery cycle on an IC engine. Appl Therm Eng 2018;128:345-56. doi:10.1016/j.applthermaleng.2017.09.012.

[2] Javanshir A, Sarunac N, Razzaghpanah Z. Thermodynamic analysis of simple and regenerative Brayton cycles for the concentrated solar power applications. Energy Convers Manag 2018;163:428-43. doi:10.1016/j.enconman.2018.02.079.

[3] Goodarzi M, Kiasat M, Khalilidehkordi E. Performance analysis of a modified regenerative Brayton and inverse Brayton cycle. Energy 2014;72:35-43. doi:10.1016/j.energy.2014.04.072.

[4] Haseli Y. Efficiency of irreversible Brayton cycles at minimum entropy generation. Appl Math Model 2016;40:8366-76. doi:10.1016/j.apm.2016.04.031.

[5] Naserian MM, Farahat S, Sarhaddi F. New exergy analysis of a regenerative closed Brayton cycle. Energy Convers Manag 2017;134:116-24. doi:10.1016/j.enconman.2016.12.020.

[6] Goodarzi M. Comparative energy analysis on a new regenerative Brayton cycle. Energy Convers Manag 2016;120:25-31. doi:https://doi.org/10.1016/j.enconman.2016.04.079.

[7] Wang W, Chen L, Sun F, Wu C. Power optimization of an endoreversible closed intercooled regenerated Brayton cycle. Int J Therm Sci 2005;44:89-94. doi:https://doi.org/10.1016/j.ijthermalsci.2004.06.002.

[8] Chen L, Wang J, Sun F. Power density analysis and optimization of an irreversible closed intercooled regenerated Brayton cycle. Math Comput Model 2008;48:527-40. doi:https://doi.org/10.1016/j.mcm.2007.09.018. 
[9] del Rio Oliveira S, Luiz Scalon V, Pereira Repinaldo V. Ecological optimization of an irreversible Brayton cycle with regeneration, inter-cooling and reheating. Appl Math Model 2015;39:6830-44. doi:https://doi.org/10.1016/j.apm.2015.02.029.

[10] Park S, Kim J, Yoon M, Rhim D, Yeom C. Thermodynamic and economic investigation of coal-fired power plant combined with various supercritical CO2 Brayton power cycle. Appl Therm Eng 2018;130:611-23. doi:https://doi.org/10.1016/j.applthermaleng.2017.10.145.

[11] Akbari AD, Mahmoudi SMS. Thermoeconomic analysis \& optimization of the combined supercritical CO2 (carbon dioxide) recompression Brayton/organic Rankine cycle. Energy 2014;78:501-12. doi:https://doi.org/10.1016/j.energy.2014.10.037.

[12] Singh OK, Kaushik SC. Thermoeconomic evaluation and optimization of a Brayton-Rankine-Kalina combined triple power cycle. Energy Convers Manag 2013;71:32-42. doi:https://doi.org/10.1016/j.enconman.2013.03.017.

[13] Durmusoglu Y, Ust Y. Thermodynamic optimization of an irreversible regenerative closed Brayton cycle based on thermoeconomic performance criterion. Appl Math Model 2014;38:5174-86. doi:https://doi.org/10.1016/j.apm.2014.04.017.

[14] Naserian MM, Farahat S, Sarhaddi F. Exergoeconomic multi objective optimization and sensitivity analysis of a regenerative Brayton cycle. Energy Convers Manag 2016;117:95-105. doi:https://doi.org/10.1016/j.enconman.2016.03.014.

[15] Rostamzadeh H, Ebadollahi M, Ghaebi H, Amidpour M, Kheiri R. Energy and exergy analysis of novel combined cooling and power (CCP) cycles. Appl Therm Eng 2017;124:152-69. doi:https://doi.org/10.1016/j.applthermaleng.2017.06.011.

[16] Gómez MR, Garcia RF, Gómez JR, Carril JC. Thermodynamic analysis of a Brayton cycle and Rankine cycle arranged in series exploiting the cold exergy of LNG (liquefied natural gas). Energy 2014;66:927-37. doi:https://doi.org/10.1016/j.energy.2013.12.036.

[17] Gholamian E, Hanafizadeh P, Ahmadi P. Advanced exergy analysis of a carbon dioxide ammonia cascade refrigeration system. Appl Therm Eng 2018;137:689-99. doi:https://doi.org/10.1016/j.applthermaleng.2018.03.055.

[18] Chen L, Ni D, Zhang Z, Sun F. Exergetic performance optimization for new combined intercooled regenerative Brayton and inverse Brayton cycles. Appl Therm Eng 2016;102:447-53. doi:https://doi.org/10.1016/j.applthermaleng.2016.03.058.

[19] Zare V, Hasanzadeh M. Energy and exergy analysis of a closed Brayton cycle-based combined cycle for solar power tower plants. Energy Convers Manag 2016;128:227-37. doi:https://doi.org/10.1016/j.enconman.2016.09.080.

[20] Cengel Y, Boles M. Thermodinamic. 7th ed. Mc Graw Hill; 2009.

\section{AUTHOR PROFILE}

Guillermo Valencia Ochoa born in Barranquilla, Colombia. Is a full-time professor at the Universidad del Atlántico. Received a degree in Mechanical Engineering from Universidad del Norte, located in Barranquilla, Colombia in 2005. Master in Mechanical Engineering from Universidad del Norte, Barranquilla, Colombia in 2008. Ph. D in Engineering from the Universidad Pontificia Bolivariana, Medellin, Colombia in 2014. He is an assistant professor of the Mechanical Engineering Program, Specializationin Energy Efficient Management and Master in Energy Management at Universidad del Atlántico.

Jorge Duarte Forero born in Barranquilla, Colombia. Is a full-time professor at the Universidad del Atlántico. Received a degree in Mechanical Engineeringfrom Universidad del Atlántico, located inBarranquilla, Colombia in 2007. Master inMechanical Engineering from Universidad delNorte, Barranquilla, Colombia in 2012. Ph. Din Engineering from the Universidad delNorte, Colombia in 2017. He is an assistantprofessor of the Mechanical EngineeringProgram.

Luis Obregon Quiñones born in Barranquilla, Colombia. Is a full-time professor at the Universidad del Atlántico. Received a degree in Chemical Engineeringfrom Universidad del Atlántico, located inBarranquilla, Colombia in 1998. Master in Chemical Engineering from Universidad de Puerto Rico, Mayaguez, Puerto Rico in 2004. Ph. D in Chemical Engineering from Universidad de Puerto Rico, Mayaguez, Puerto Rico in 2009. He is an associateprofessor of the Chemical EngineeringProgram. 